\title{
Cellular distribution, developmental changes and effects of cryptorchidism on uridine kinase in the rat testis
}

\author{
T. B. Haugen, V. Hansson and P. Fritzson \\ Institute of Medical Biochemistry, University of Oslo, P.O. Box. 1112 Blindern, 0317 Oslo 3, \\ Norway
}

\begin{abstract}
Summary. High specific activity of uridine kinase was found in cultured peritubular cells $(3.0 \mathrm{nmol} / \mathrm{min}$ per $\mathrm{mg}$ protein) which was more than 3-fold higher than that found in cultured Sertoli cells $(0.79 \mathrm{nmol} / \mathrm{min}$ per $\mathrm{mg}$ protein). In the various classes of germ cells a decrease in specific uridine kinase activity was associated with increased maturity of the cells, primary spermatocytes, round spermatids and spermatozoa showing $1 \cdot 3$, 0.65 and $0.16 \mathrm{nmol} / \mathrm{min}$ per $\mathrm{mg}$ protein, respectively. A relationship between uridine kinase activity and the rate of RNA synthesis in these cells is suggested. A decrease in specific uridine kinase activity in testis with increasing age supports the finding of lower uridine kinase in mature germ cells than in earlier germ cells and somatic cells. This finding is further supported by the observation that cryptorchidism, which is associated with a time-dependent depletion of germ cells, resulted in an increase in specific uridine kinase activity. The results indicate that pyrimidine salvage is important in earlier germ cells, as well as in somatic cells in the testis, to produce substrates for nucleic acid synthesis.
\end{abstract}

Keywords: Sertoli cells; peritubular cells; germ cells; cryptorchidism; uridine kinase; pyrimidine salvage

\section{Introduction}

Testis is a tissue with high degree of cell renewal and nucleic acid turnover. This requires an extensive degradation as well as synthesis of nucleotides. Little is known about the testicular enzymes involved in these processes. We have previously demonstrated the presence of the deoxyribonucleoside-activated nucleotidase (DAN) (EC 3.1.3.31) in rat testis (Haugen et al., $1987 \mathrm{a}, \mathrm{b})$, an enzyme which catalyses the dephosphorylation of various 5 '- and $3^{\prime}$-nucleoside monophosphates in the cytosol (Fritzson, 1978). The nucleosides produced by DAN activity may be degraded further, or they may act as substrates for enzymes of the nucleoside salvage pathway. One of these enzymes is uridine kinase (ATP:uridine 5'-phosphotransferase, EC 2.7.1.48) which catalyses the phosphorylation of uridine and cytidine to their respective monophosphates. This activity is rate-limiting in the salvage pathway for pyrimidine nucleotide biosynthesis (Anderson, 1973).

DAN activity is mainly located in the somatic cells (Sertoli cells, peritubular cells) of the testis with particularly high specific activity in the Sertoli cells (Haugen et al., 1987a). Since little or no activity was found in the germ cells examined (primary spermatocytes, round spermatids), we have suggested that the Sertoli cells are involved in providing nucleosides for the germ cells. A prerequisite for such a relationship is that the germ cells contain enzymes for reutilization of nucleosides or bases. Several workers have reported that rat testis has a high activity of hypoxanthine-guanine phosphoribosyltransferase (HGPRT) (Adams \& Harkness, 1976; Natsumeda et al., 1984; Allsop \& Watts, 1986), the rate-limiting enzyme of the purine salvage pathway. Apart from a study of Machovich \& Greengard (1972), who found a very low thymidine kinase activity in adult rat testis, 
no information about pyrimidine salvage enzymes in testis has been reported. In the present work we studied developmental changes and cellular distribution of uridine kinase activity in the rat testis. Since fixation of the testis within the abdomen (cryptorchidism) causes selective germ cell depletion, we also examined the effects of experimental cryptorchidism on the activity of uridine kinase in testis.

\section{Materials and Methods}

Animals and reagents. Sprague-Dawley rats were supplied by Møllegaards Breeding Centre Ltd, Ejby, Denmark. Sertoli cells and peritubular cells were isolated from 19-day-old rats, and 32-day-old rats were used for isolating primary spermatocytes and round spermatids. Epididymal spermatozoa were prepared from adult rats (about 100 days of age).

Rats were made unilaterally cryptorchid at the age of 17 or 60 days by attaching the testis on one side to the inner lateral abdominal wall. Surgical techniques and treatment of the animals were carried out as described by Karpe $e t$ al. (1981). The testes were used for cytosol preparation immediately after killing.

Collagenase, DNase, bovine serum albumin (BSA), trypsin inhibitor (type 1-S), uridine and ATP were obtained from Sigma Chemical Co. (St Louis, MO, U.S.A.). Hanks' Balanced Salt Solution (HBSS), Eagle's Minimal Essential Medium (MEM) and fetal calf serum were from Gibco (Grand Island, NY, U.S.A.). Trypsin was purchased from Difco (Detroit, MI, U.S.A.) and $\left[2-{ }^{14} \mathrm{C}\right]$ uridine from Amersham International plc (Amersham, Bucks, U.K.).

Cell preparation. The isolation of Sertoli cells was carried out as described by Dorrington et al. (1975) by treatment of the decapsulated testis with trypsin, DNase and collagenase. After 4 days in culture, germ cells were removed by mechanical agitation. The remaining Sertoli cell sheet was washed with $0.25 \mathrm{M}$-sucrose $/ 50 \mathrm{~mm}$-Tris- $\mathrm{HCl}, \mathrm{pH} 7.4$ (Medium TBS) and recovered by scraping with a rubber policeman. The contamination of germ cells in the Sertoli cell preparation was less than $2 \%$.

Peritubular cells were isolated by the method of Hutson \& Stocco (1981). Cells were cultured until the state of confluence was reached, washed with TBS and scraped from the dishes. Sertoli cells containing lipid droplets were occasionally seen $(<1 \%)$ in these preparations.

The fractionation of germ cells into primary spermatocytes (PS) and round spermatids (RST) was performed in BSA gradients at unit gravity in a velocity sedimentation cell separator (STA-PUT) according to Miller \& Phillips (1969), with the modification of Grootegoed et al. (1977). BSA gradients ranging from 1.0 to $3.2 \%$ were prepared in HBSS, and $\mathrm{pH}$ was maintained at 6.9 to prevent clumping of cells. The cells were collected at a flow rate of $20 \mathrm{ml} / \mathrm{min}$. The isolated cell fractions were centrifuged at $300 \mathrm{~g}$ for $5 \mathrm{~min}$ and washed three times with Medium TBS. The purities of the PS and RST fractions were $80-90 \%$ and $70-85 \%$, respectively.

Spermatozoa were prepared by cutting the cauda epididymidis into pieces in Petri dishes containing Medium TBS. The resulting suspension of spermatozoa was separated from epididymal fragments by sedimentation at unit gravity and then centrifuged at $300 \mathrm{~g}$ for $5 \mathrm{~min}$. The cells were washed once with Medium TBS.

Cytosol preparation. The cells were disrupted by sonication at maximal output with Kontes Micro-Ultrasonic Disrupter in Medium TBS for $30 \mathrm{sec}$ at $0^{\circ} \mathrm{C}$. Decapsulated testis was homogenized in 10 volumes of Medium TBS with an Ultra-Turrax homogenizer (two 10-sec bursts). The sonicates and homogenates were centrifuged at $105000 \mathrm{~g}$ for $1 \mathrm{~h}$ to obtain the cytosol fractions.

Uridine kinase. Uridine kinase was assayed by measuring the conversion of $\left[{ }^{14} \mathrm{C}\right]$ uridine to phosphorylated products. The reaction mixture (total volume $250 \mu \mathrm{l}$ ) contained $50 \mathrm{mM}$-Tris- $\mathrm{HCl}, \mathrm{pH} 7.5,0.5 \mathrm{mg}$ bovine serum albumin, $1 \mathrm{~mm}$-dithiothreitol, $10 \mathrm{mM}-\mathrm{MgCl}_{2}, 5 \mathrm{mM}$-ATP, $0.4 \mathrm{~mm}$-uridine containing $0.75 \mu \mathrm{Ci}\left[2-{ }^{14} \mathrm{C}\right]$ uridine and $25150 \mu \mathrm{l}$ cytosol. Incubation was carried out at $37^{\circ} \mathrm{C}$ for $10 \mathrm{~min}$. The reaction was stopped by heating in boiling water for $2 \mathrm{~min}, 4.75 \mathrm{ml} 1 \mathrm{~mm}$-uridine were added, the mixture centrifuged, and $1 \mathrm{ml}$ was passed through a $2.3-\mathrm{cm}$ diameter DEAE-cellulose disc (Whatman DE 81) that had been pretreated with 1 mM-uridine. The discs were washed with two $10-\mathrm{ml}$ portions of water, then soaked in $50 \mathrm{ml}$ water, drained and placed in counting vials. The elution and counting of radioactive nucleotides formed were carried out as described by Ives et al. (1969).

$\mathrm{Mn}^{2+}$-dependent adenylate cyclase assay. $\mathrm{Mn}^{2+}$-dependent adenylate cyclase (EC 4.6.1.1) activity was measured in the cytosols as described previously (Haugen et al., 1987b).

Protein determination. Protein was determined in the cytosol fractions by the method of Lowry et al. (1951) with bovine serum albumin as the standard.

\section{Results}

\section{Developmental changes in uridine kinase in rat testis and effects of cryptorchidism}

There were no significant differences in uridine kinase activities and weights between the testes of normal and sham-operated rats and between the scrotal testes of normal and unilaterally 


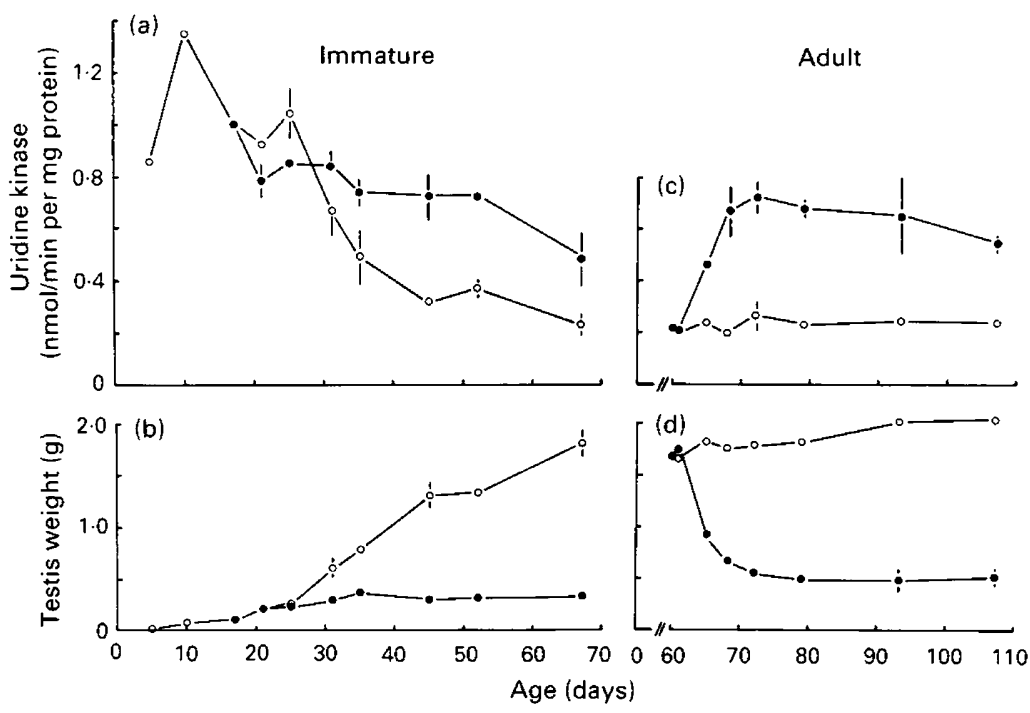

Fig. 1. Age-dependent changes in specific uridine kinase activity (a,c) and testicular weight $(\mathrm{b}, \mathrm{d})$ of scrotal (control; $O$ ) and cryptorchid (O) testes. Rats were made unilaterally cryptorchid at Day $17(\mathrm{a}, \mathrm{b})$ or Day $60(\mathrm{c}, \mathrm{d})$. Each point represents the mean $\pm \mathrm{s} . \mathrm{d}$. of the results from 3 individual animals, except at Days 5 and 10 for which the value is the mean from pooled cytosols from 10 rats. Enzyme activities were measured at protein concentrations giving constant specific activities.

cryptorchid animals. The values presented for the scrotal testes in Fig. 1 are therefore representative for normal development.

Between Day 5 and Day 10 there was an increase in specific activity after which a high activity level was maintained for 15 days (Fig. 1a). A gradual decrease in uridine kinase activity was seen from Day 25 to 45 which coincides with a rapid increase in testicular weight (Fig. lb). This increase was accompanied by a parallel increase in germ cell specific $\mathrm{Mn}^{2+}$-dependent adenylate cyclase (data not shown). The specific uridine kinase activity remained constant and low after Day 67, as illustrated in Fig. $1 \mathrm{c}$ for adult rats. In this period also the testicular weight was almost constant (Fig. 1d).

The marked decrease in specific uridine kinase activity observed during normal development was prevented during cryptorchidism, although a slow decline in activity started immediately after the operation (Fig. 1a). At the end of the experimental period (Day 67), the specific activity in the abdominal testis was about twice that in the scrotal testis. The initial slight activity decrease in the abdominal testis coincided with a small increase in testicular weight (Fig. 1b).

In adult rats, cryptorchidism was followed by a dramatic increase in specific uridine kinase activity during the first 12 days, thereafter the specific activity decreased slightly (Fig. 1c). At 50 days after operation, the activity in the abdominal testis was approximately the same in the immature and adult rats. The rapid depletion of germ cells in the abdominal, mature testis shortly after the operation was reflected by the decrease in testis weight (Fig. 1d), as well as in $\mathrm{Mn}^{2+}$-dependent adenylate cyclase activity (data not shown).

\section{Cellular distribution of uridine kinase in rat testis}

In all the cell types isolated from seminiferous tubules a significant specific activity of uridine kinase was found (Table 1). Activity in the cultured peritubular cells was 3-fold higher than that in cultured Sertoli cells. In the germ cells there was a decrease in activity with the increasing order of maturity of the cells: specific activity was highest in primary spermatocytes and lowest in the spermatozoa. 
Table 1. Activity of uridine kinase in cells from rat testis

\begin{tabular}{lc}
\hline \multicolumn{1}{c}{ Cell type } & $\begin{array}{c}\text { Enzyme activity } \\
\text { (nmol/min per mg protein) }\end{array}$ \\
\hline Sertoli cells & $0 \cdot 79 \pm 0.15(6)$ \\
Peritubular cells & $3 \cdot 0 \pm 0.6(5)$ \\
Primary spermatocytes & $1 \cdot 3 \pm 0.2(5)$ \\
Round spermatids & $0 \cdot 65 \pm 0.12(8)$ \\
Epididymal spermatozoa & $0.16 \pm 0.01(2)$ \\
\hline
\end{tabular}

Values are means \pm s.d. for the number of experiments shown in parentheses. Enzyme activities were measured at protein concentrations giving constant specific activities.

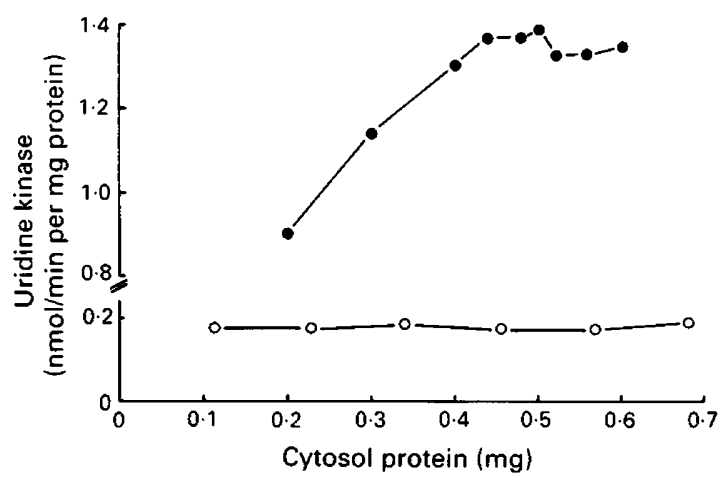

Fig. 2. Specific uridine kinase activity as a function of the amount of testicular cytosol protein from $10(\bigcirc)$ and $60(\bigcirc)$-day-old rats, in the incubation mixture. The values are representative of 3 experiments.

\section{Influence of cytosol concentration on uridine kinase assay}

During the studies of enzyme activity in the different cell types of testis, it became apparent that the specific activity measured in Sertoli cells, primary spermatocytes and to a lesser extent in round spermatids, was dependent on the cytosol concentration in the assay being below a certain concentration. In contrast, peritubular cells and spermatozoa showed proportionality between enzyme activity and cytosol concentration in the incubation mixture. The dependence on cytosol concentration was also encountered with cytosols prepared from immature testis homogenates but not when mature testis was the enzyme source (Fig. 2). In immature testis there was an increase in specific activity with increasing amount of protein up to $0.45 \mathrm{mg}$, whereas the specific activity in adult testis was constant. The enzyme activity was proportional with incubation time with cytosols from the immature and adult testes, even when immature testis concentrations were below that giving maximal specific activity (data not shown).

\section{Discussion}

In this study we found that the measured specific activity of uridine kinase in some of the cell types, as well as that in immature testis cytosols, was dependent on cytosol concentration in the assay. At 
present, no explanation of this observation is known, but it may be due to factor(s) present in the cytosol which influence the aggregational state of the enzyme. It has been shown by other workers that uridine kinase from Ehrlich ascites tumour cells exists as multiple interconvertible polymeric forms (Payne et al., 1985; Cheng et al., 1986). Both temperature and ligands (ATP, CTP, UTP) affect the polymerization of the enzyme, and the monomer was found to have little or no activity (Cheng et al., 1986).

Our observation that uridine kinase activity was linear with time indicates that the lack of proportionality between enzyme activity and cytosol concentration is not due to degradation of substrates or products by other enzymic reactions. In this connection it should be noted that an alkaline nucleotidase present in the cytosol and with high activity towards UMP, is strongly inhibited by ATP at the concentration used in the uridine kinase assay (Fritzson et al., 1986).

Except during fetal development, normal tissues usually have higher activity of uridine kinase than of the pathway for de-novo UMP synthesis (Weber et al., 1978; Herzfeld \& Raper, 1979; Denton et al., 1982). Furthermore, elevated activities of uridine kinase are found in tissues and cells undergoing rapid proliferation, like transformed cells or tumour cells (Ahmed et al., 1982; Ahmed, 1984), stimulated lymphocytes (Peters et al., 1983) and regenerating liver (Sköld, 1960; Bresnick, 1965; Arima et al., 1972; Weber et al., 1978; P. Fritzson \& T. B. Haugen, unpublished observations). The specific activity of uridine kinase found in primary spermatocytes in the present study was in the same range as that reported for several rat hepatoma cell lines (Fulchignoni-Lataud \& Roux, 1984) as well as for rat spleen (Fritzson, 1978). This suggests that high uridine kinase activity, reflecting high capacity of uridine salvage, is important for the extensive RNA synthesis which takes place in these germ cells (Fox \& Fox, 1967). The rate of RNA synthesis shows a marked decrease in the order primary spermatocytes, round spermatids, and spermatozoa, the last having no synthesis of RNA. The activity of uridine kinase in these classes of germ cells decreased in the same order, which could be interpreted as further evidence for a relationship between uridine kinase and the rate of RNA synthesis in these cells. However, the rate of RNA synthesis in round spermatids in mouse is reported to be of the same magnitude as that in primary spermatocytes when expressed per DNA content (Geremia et al., 1977).

The specific uridine kinase activity in peritubular cells was surprisingly high. Since these cells are rapidly proliferating in culture but not in intact tissue, it is uncertain whether similar high uridine kinase activity is present in these cells in vivo. The specific activity of uridine kinase in the cultured Sertoli cells was similar to that of round spermatids. Sertoli cells do not proliferate in vivo (after 15 days of age) (Steinberger \& Steinberger, 1971) or under the culture conditions used. The activity of uridine kinase measured in these cells may therefore be representative of non-dividing Sertoli cells.

Additional evidence for high specific uridine kinase activity in the somatic cells and low specific activity in mature germ cells was obtained by our studies of the enzyme activity during testicular development as well as during cryptorchidism. The presence of an increased number of mature germ cells in testes from older animals was associated with decreased specific uridine kinase activity, whereas the depletion of germ cells occurring during cryptorchidism was accompanied by increased activity. Thus, variations in uridine kinase activity during development and cryptorchidism appear to be primarily due to changes in cellular composition of the testis. Direct effects of temperature on uridine kinase activity in somatic cells cannot be completely excluded.

We have previously shown that Sertoli cells have high capacity for dephosphorylating nucleoside monophosphates through the action of DAN and have suggested that the Sertoli cells may supply the germ cells with nucleosides (Haugen et al., 1987a). This hypothesis is in accordance with the assumption that the main function of the Sertoli cells is to provide nutrients (energy substrates) and metabolic precursors for germ cells inside the blood-testis barrier (Jutte et al., 1982). Therefore, utilization of preformed nucleosides/bases instead of, or in addition to, nucleotide synthesis by the energy-consuming de-novo pathway may be necessary for synthesis of nucleic acid precursors in germ cells. The suggested function of DAN in Sertoli cells is analogous to 
a previous conclusion based on experiments with regenerating rat liver that a main metabolic function of cytosolic 5'-nucleotidase (an enzyme different from DAN) is the production of inosine for export from the liver to other tissues (Tjernshaugen \& Fritzson, 1984).

Although HGPRT activity has not been investigated in fractionated cell types from seminiferous tubules, the presence of high enzyme activity in isolated seminiferous tubules as well as in Leydig cells from rat testis has been described (Adams \& Harkness, 1976; Allsop \& Watts, 1986). Furthermore, radioautographic studies of the location of HGPRT activity in human testis have indicated high activity in all testicular cell types, with the exception of spermatozoa, which showed no activity. Highest concentration was detected in the spermatogonia (Adams \& Harkness, 1976), the basal stem cells in the seminiferous tubules. These findings, together with the present results, show that germ cells with significant nucleic acid synthesis exhibit both the purine and pyrimidine salvage pathways.

In summary, we have shown that uridine kinase activity is widely distributed in testicular cells. In germ cells this activity seems to be related to RNA synthesis, indicating that pyrimidine salvage is important in these cells for production of nucleotides for nucleic acid synthesis.

We thank Mrs Marit Haug and Mrs Gerd Rønneberg for excellent technical assistance. Financial support from Professor Einar og hustru Ebba Langfeldts fond is gratefully acknowledged.

\section{References}

Adams, A. \& Harkness, R.A. (1976) Developmental changes in purine phosphoribosyltransferases in human and rat tissues. Biochem. J. 160, 565-576.

Ahmed, N.K. (1984) Enzymes of the de novo and salvage pathways for pyrimidine biosynthesis in normal colon, colon carcinoma, and xenografts. Cancer 54, 1370-1373.

Ahmed, N.K., Haggitt, R.C. \& Welch, A.D. (1982) Enzymes of salvage and de novo pathways of synthesis of pyrimidine nucleotides in human colorectal adenocarcinomas. Biochem. Pharmacol. 31, 2485-2488.

Allsop, J. \& Watts, R.W.E. (1986) Purine phosphoribosyltransferase (EC 2.4.2.7 and 2.4.2.8) and purine de novo synthesis activity in rat testicular tissue at different stages of development, and their correlation with the circulating levels of gonadotrophins and testosterone, and with structural changes. Differentiation 32, 144-147.

Anderson, E.P. (1973) Nucleoside and nucleotide kinases. In The Enzymes, 3rd edn, vol. 9, pp. 49-96. Ed. P.D. Boyer. Academic Press, New York.

Arima, T., Shirasaka, T., Okuda, H. \& Fujii, S. (1972) Studies on a reciprocal relationship between nucleoside kinases and 5'-nucleotidase. Biochim. Biophys. Acta 277, 15-24.

Bresnick, E. (1965) Early changes in pyrimidine biosynthesis after partial hepatectomy. J. biol. Chem. 240, $2550-2556$.

Cheng, N., Payne, R.C. \& Traut, T.W. (1986) Regulation of uridine kinase. Evidence for a regulatory site. $J$. biol. Chem. 261, 13006-13012.

Denton, J.E., Lui, M.S., Aoki, T., Sebolt, J., Takeda, E., Eble, J.N., Glover, J.L. \& Weber, G. (1982) Enzymology of pyrimidine and carbohydrate metabolism in human colon carcinomas. Cancer Res. 42, 1176-1183.
Dorrington, J.H., Roller, N.F. \& Fritz, I.B. (1975) Effects of follicle-stimulating hormone on cultures of Sertoli cell preparations. Molec. cell. Endocrinol. 3, 57-70.

Fox, B.W. \& Fox, M. (1967) Biochemical aspects of the actions of drugs on spermatogenesis. Pharmacol. Rev. 19, 2I-57.

Fritzson, P. (1978) Regulation of nucleotidase activities in animal tissues. Adv. Enzyme Regul. 16, 43-61.

Fritzson, P., Haugen, T.B. \& Tjernshaugen, H. (1986) The presence and activity in normal and regenerating rat liver postmicrosomal supernatant fraction of an enzyme with properties similar to those of membrane-bound 5'-nucleotidase. Biochem. J. 239, 185-190.

Fulchignoni-Lataud, M.-C. \& Roux, J.M. 1984) Uridine kinase molecular species and uridine uptake in some variants of rat hepatomas. J. cell. Physiol. 118, 34-38.

Geremia, R., Boitani, C., Conti, M. \& Monesi, V. (1977) RNA-synthesis in spermatocytes and spermatids and preservation of meiotic RNA during spermiogenesis in mouse. Cell Differentiation 5, 343-355.

Grootegoed, J.A., Grollé-Hey, A.H., Rommerts, F.F.G. \& van der Molen, H.J. (1977) Ribonucleic acid synthesis in vitro in primary spermatocytes isolated from rat testis. Biochem. J. 168, 23-31.

Haugen, T.B., Fritzson, P. \& Hansson, V. (1987a) Cellular localization and developmental changes of deoxyribonucleoside-activated nucleotidase in the rat testis. Int. J. Biochem. 19, 193-196.

Haugen, T.B., Levy, F.O., Hansson, V. \& Fritzson, P. (1987b) Effects of cryptorchidism and orchidopexy on deoxyribonucleoside-activated nucleotidase (DAN) in the rat testis. Int. J. Biochem. 19, 1023-1027.

Herzfeld, A. \& Raper, S.M. (1979) Uridine kinase activities in developing, adult and neoplastic rat tissues. Biochem. J. 182, 771-778. 
Hutson, J.C. \& Stocco, D.M. (1981) Peritubular cell influence on the efficiency of androgen-binding protein secretion by Sertoli cells in culture. Endocrinology 108, 1362-1368.

Ives, D.H., Durham, J.P. \& Tucker, V.S. (1969) Rapid determination of nucleoside kinase and nucleotidase activities with tritium labeled substrates. Analyt. Biochem. 28, 192-205.

Jutte, N.H.P.M., Jansen, R., Grootegoed, J.A., Rommerts, F.F.G., Clausen, O.P.F. \& van der Molen, H.J. (1982) Regulation of survival of rat pachytene spermatocytes by lactate supply from Sertoli cells. $J$. Reprod. Fert. 65, 431-438.

Karpe, B., Plöen, L., Hagenäs, L. \& Ritzen, E.M. (1981) Recovery of testicular functions after surgical treatment of experimental cryptorchidism in the rat. Int. J. Androl. 4, 145-160.

Lowry, O.H., Rosebrough, N.J., Farr, A.L. \& Randall, R.L. (1951) Protein measurement with the Folin phenol reagent. J. biol. Chem. 193, 265-275.

Machovich, R. \& Greengard, O. (1972) Thymidine kinase in rat tissues during growth and differentiation. Biochim. Biophys. Acta 286, 375-381.

Miller, R.G. \& Phillips, R.A. (1969) Separation of cells by velocity sedimentation. J. cell. Physiol. 73, 191-201.

Natsumeda, Y., Prajda, N., Donohue, J.P., Glover, J.L. \& Weber, G. (1984) Enzymic capacities of purine de novo and salvage pathways for nucleotide synthesis in normal and neoplastic tissues. Cancer Res. 44, $2475-2479$.

Payne, R.C., Cheng, N. \& Traut, T.W. (1985) Uridine kinase from Ehrlich ascites carcinoma. Purification and properties of homogeneous enzyme. J. biol. Chem. 260, 10242-10247.

Peters, G.J., Oosterhof, A. \& Veerkamp, J.H. (1983) Pyrimidine metabolism in peripheral and phytohemagglutinin-stimulated mammalian lymphocytes. Int. J. Biochem. 15, 51-55.

Sköld, O. (1960) Enzymes of uracil metabolism in tissues with different growth characteristics. Biochim. Biophys. Acta 44, 1-12.

Steinberger, A. \& Steinberger, E. (1971) Replication pattern of Sertoli cells in maturing rat testis in vivo and in organ culture. Biol. Reprod. 4, 84-87.

Tjernshaugen, H. \& Fritzson, P. (1984) Activity of cytosolic 5'-nucleotidase in regenerating rat liver after partial hepatectomy. Int. J. Biochem. 16, $607-613$.

Weber, G., Shiotani, T., Kizaki, H., Tzeng, D., Williams, J.C. \& Gladstone, N. (1978) Biochemical strategy of the genome as expressed in regulation of pyrimidine metabolism. Adv. Enzyme Regul. 16, 3-19.

Received 14 October 1987 